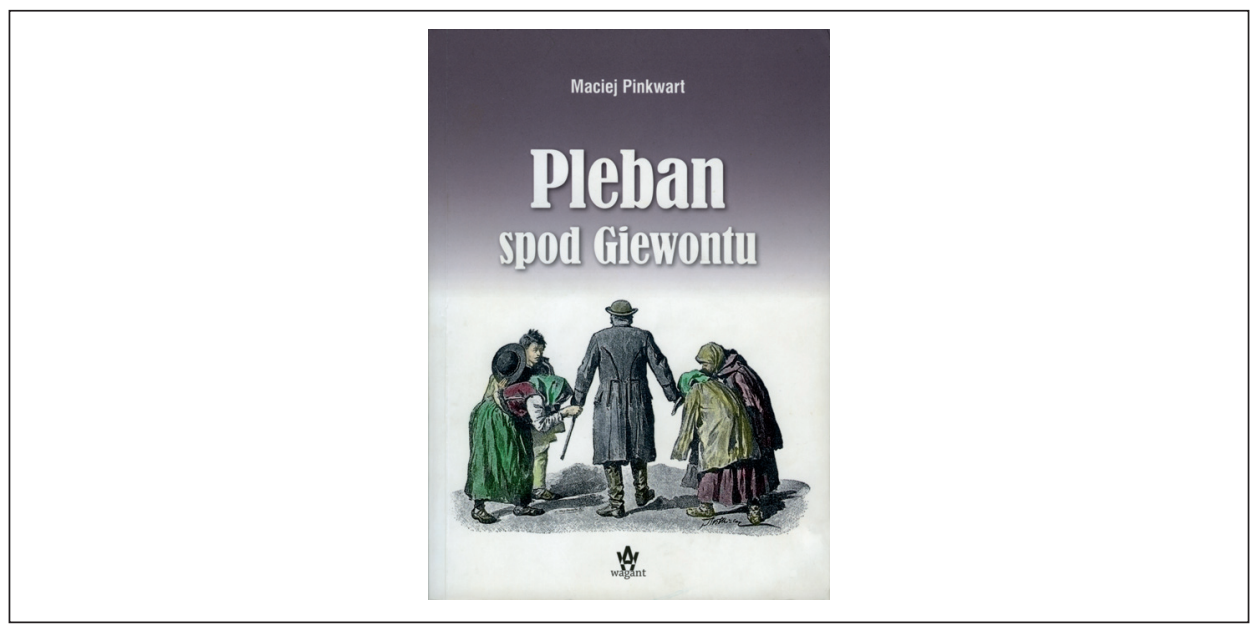

\title{
Jegomość z parafii na końcu świata, czyli pod Giewontem
}

DOl: 10.19195/2084-4107.12.28

[rec.:] Maciej Pinkwart, Pleban spod Giewontu, Wydawnictwo Wagant, Nowy Targ 2017, ss. 536.

The reverend from the parish at the end of the world, that is, from Giewont

Słowa-klucze: Tatry, ks. Józef Stolarczyk, parafia Zakopane, historia, kultura

Keywords: Tatras, Father Józef Stolarczyk, Zakopane parish, history, culture

„Józef pod Giewontem” albo „Pleban pod Giewontem” — tak podpisywał swoją korespondencję bohater imponującej monografii Macieja Pinkwarta Pleban spod Giewontu ${ }^{1}$. Jak nietrudno się domyślić, jest nim legendarny (pierwszy) proboszcz Zakopanego, ks. Józef Stolarczyk, który pracował „na końcu świata” (jak określano wówczas niedużą osadę pod Giewontem) w latach 1847-1893. Notabene w tym okresie podhalański „koniec świata” sukcesywnie przybliżał się do miłośników Tatr, kuracjuszy i turystów, głównie za sprawą uruchomienia kolei na trasie Kraków-Chabówka (1884) oraz modernizacji drogi z Nowego Targu do Zakopanego (1884).

Widzimy ubogą wioskę u stóp niemal jeszcze dziewiczych szczytów tatrzańskich, gdzie niezbyt cywilizowani mieszkańcy często-gęsto przymierają głodem, swoje sprawy regulują w zgodzie z naturą, ale nieko-

1 Publikacja w 2018 roku otrzymała Nagrodę Literacką Zakopanego. 
niecznie według praw ludzkich i boskich, gdzie ostoją sprawiedliwości jest własna ciupaga, a w nieustającej walce z surową przyrodą i półdzikimi sąsiadami kształtują się ludzkie charaktery (s. 187)

— niezwykle obrazowa narracja Pinkwarta, odzwierciedlająca historyczne realia tamtych czasów, sprawia, że książkę czyta się z zapartym tchem. Warto pochwalić walor poznawczy z rozbudowanymi odwołaniami, wybiegającymi w historyczne, polityczne i ekonomiczne uwarunkowania dziejów regionu oraz funkcjonowania Kościoła w XIX wieku. Z całą pewnością publikacja ta wykracza poza modelowy wzorzec biografii i zawiera bogaty materiał źródłowy, uzupełniający portret Stolarczyka.

Przejrzyście skomponowana i niezwykle przemyślana w linii konstrukcyjnej monografia jest niebanalną opowieścią o wybitnym przedstawicielu zakopiańskiej elity. Część pierwsza książki prezentuje sylwetkę Stolarczyka, jego biografię zarysowaną na bogatym tle historycznym — z licznymi dygresjami odkrywającymi ważne karty historii Kościoła na Podhalu — charakteryzuje działalność duszpasterską, opierając się na bogatym materiale źródłowym, opisuje kontakty z najważniejszymi współtwórcami życia umysłowego na Podhalu, relacje z wiernymi, przedsięwzięcia i inicjatywy duszpasterskie, wskazuje fascynacje tatrzańskie i zamiłowanie do turystyki górskiej, egzotyczne podróże zagraniczne, układy rodzinne i towarzyskie, a także przedstawia szczegóły związane ze śmiercią i pogrzebem Stolarczyka oraz utrwalanie pamięci po zasłużonym kapłanie.

Część drugą wypełnia starannie opatrzona uwagami edytorskimi reedycja Kroniki parafi zakopiańskiej Józefa Stolarczyka — głównego dokumentu źródłowego dziejów Zakopanego (jak twierdzi Pinkwart: „,Tego dokumentu nie można brać do ręki bez wzruszenia") — której pierwsze krytyczne wydanie (z rękopisu) w opracowaniu Pinkwarta ukazało się w 1986 roku. Pierwszego komentarza tego dokumentu dokonał Walery Eliasz na łamach „Biesiady Literackiej” w 1897 roku, stąd też druga edycja Kroniki — w 1997 roku poszerzona o korespondencję Stolarczyka z Eliaszem. Natomiast w omawianej (ósmej) edycji znajdziemy ponadto zapisane przez świadków fragmenty kazań Stolarczyka oraz materiały na temat życia i działalności plebana spod Giewontu.

W części trzeciej autor publikuje dokumenty źródłowe ilustrujące działalność Stolarczyka i w dużej mierze jest to materiał publikowany po raz pierwszy — są to rękopisy z archiwum Muzeum Tatrzańskiego, parafii Najświętszej Rodziny i Ośrodka Dokumentacji Tatrzańskiej TPN w Zakopanem, Archiwum Narodowego w Krakowie, archiwum kurii tarnowskiej i krakowskiej. Na dowartościowanie zasługuje precyzja edytorska, umiejętność zastosowania przemyślanych zasad pisowni, wprowadzenia skrótów i odpowiednich przypisów. Ten fragment monografii stanowi nieoceniony materiał dla badaczy dziejów Podhala, turystyki górskiej na Podhalu, a także Zakopanego jako fenomenu kulturowego u schyłku XIX wieku.

Prezentując niebagatelne zasługi Stolarczyka dla rozwoju miejscowości i regionu, Pinkwart uznaje w nim jednego z prekursorów „cywilizowania” Podhala. 
Autor jako wydawca Kroniki zakopiańskiej z dużym znawstwem tematu rysuje sylwetkę plebana spod Giewontu wielostronnie — w różnych aspektach jego działalności kapłańskiej i społecznej. Zakopiański proboszcz był bowiem jednym z czołowych luminarzy ówczesnego rozwoju kulturalnego i cywilizacyjnego; jako duszpasterz społeczności pielęgnującej niezależność wewnętrzną starał się być jej opiekunem i wychowawcą; był wrażliwy na ich potrzeby i odpowiadał na problemy (między innymi skrupulatnie odnotowywał biedę materialną).

Poznawczo-dokumentacyjną wartość książki dopełnia znakomity aspekt anegdotyczny. Pinkwart, przywołując Na przetęczy Stanisława Witkiewicza, podkreśla niełatwe warunki, w jakich przyszło Stolarczykowi duszpasterzować przy pomocy niekonwencjonalnych metod:

parafianie przyglądali się temu z szyderstwem i pogardą, a zapalając fajki o świece i lampki święcone, szli w hale paść owce, walczyć z niedźwiedziami, kopać rudę w Kościeliskach, uganiać się za dzikim capem? Lub grzebać świstaki, w którego sadle widzieli daleko więcej mocy tajemniczej niż w mszach i koronkach².

W anegdocie zapisał się nie tylko gest przyzwalania palaczom na uprawianie nawyku w świątyni (notabene walcząc z nałogami wiernych, Stolarczyk od 1857 roku prowadził tak zwaną Książkę Wstrzemięźliwości, czyli listę osób, które wyrzekły się spożywania alkoholu), ale też bezzwrotne pożyczki pieniędzy w zamian za przystąpienie do spowiedzi.

Stolarczyk był przede wszystkim apostołem miejscowej ludności, lecz jednocześnie jako zakopiański „pozytywista” w 1848 roku zainicjował edukację dzieci góralskich (początkowo uczył w tej szkole osobiście, potem wspólnie z organistą, a z czasem zaangażowano w to zawodowego nauczyciela). Warto jednak pamiętać, że był również miłośnikiem Tatr, zachęcającym mieszkańców regionu (zarówno pasterzy, jak i kłusowników) do prowadzenia turystów w góry. Był też jednym z założycieli Towarzystwa Tatrzańskiego i członkiem honorowym Towarzystwa Muzeum Tatrzańskiego. Jak pisał: „Poznałem całe Tatry”; był na Świnicy, Łomnicy, na Gerlachu, Lodowym, Wysokiej. Był także prekursorem powstania TOPR-u.

Wykorzystując wcześniejsze opracowania (Stanisława Witkiewicza, Ferdynanda Hoesicka, Jalu Kurka i Włodzimierza Wnuka), bezkrytycznie idealizujące sylwetkę Plebana, Pinkwart z naukowym dystansem prostuje dotychczasowe nieścisłości biograficzne, w niektórych przypadkach „demitologizując” mit proboszcza - udowadnia między innymi, że Stolarczyk nie zbudował kościoła przy ulicy Kościeliskiej (był budowniczym plebanii oraz inicjatorem budowy murowanego kościoła przy Krupówkach, którego budowa została ukończona już po jego śmierci), lecz ową demaskację autor złagodził stwierdzeniem, że ,zbudował Kościół w sercach parafian" - tak emocjonalnie z nim związanych, że gdy wyjechał na pielgrzymkę do Ziemi Świętej, parafianie codziennie modlili się o jego szczęśliwy powrót.

2 S. Witkiewicz, Na przełęczy. Wrażenia i obrazy z Tatr, Warszawa 2017, s. 73. 
Jak z Ambony szanowny Pasterz wpływa zbawiennie na parafian swoich, tak nie mniej korzystnie działa na nich w codziennym przestawaniu z niemi. Wyższe wykształcenie naukowe, wesoły i miły humor, szacunek, jaki sobie umiał zjednać powszechnie, nie przeszkadzają mu bynajmniej, iż obcuje najchętniej z poruczonym swej pieczy ludem, z którym w prawdziwie patriarchalnych zostaje stosunkach ${ }^{3}$.

Odwiedzający drewniany kościółek przy ulicy Kościeliskiej w Zakopanem muszą się jednak zmagać z frapującym pytaniem, jak ów postawny mężczyzna, przewyższający górali wzrostem o głowę, mieścił się na tej malutkiej, niewysokiej, drewnianej ambonce. Książka Pinkwarta (w której można znaleźć również ciekawy materiał ikonograficzny) potwierdza, że mieścił się skutecznie.

Matgorzata Łoboz

ORCID: 0000-0002-0705-8219

${ }^{3}$ M. Steczkowska, Obrazy z podróży do Tatrów, Kraków 1858, s. 450. 